\title{
Gastrointestinal Intervention
}

\author{
journal homepage: www. gi-intervention.org
}

Review Article

\section{Endoscopic approaches to afferent and Roux-en-Y limb obstruction}

\author{
Richard A. Kozarek
}

\section{A B S T R A C T}

Afferent limb syndrome can be seen following Billroth II gastric resection, Whipple procedure with duodenojejunostomy, or in association with an obstructed Roux-en-Y limb following hepaticojejunostomy. This syndrome classically presents with jaundice or cholangitis but may also be associated with abdominal pain alone or pancreatitis, especially in patients with surgically created pancreaticojejunostomies. Obstructions may be a consequence of benign or malignant disorders. Historically treated with surgery or percutaneous transhepatic biliary drainage, this review describes currently applied and evolving endoscopic techniques to include balloon dilation, double pigtail plastic stent placement, and insertion of self-expandable metal stents or lumen-apposing stents.

Copyright (C) 2016, Society of Gastrointestinal Intervention. All rights reserved.

Keywords: Afferent limb; Biliary obstruction; Cholangitis; Roux-en-Y; Small bowel obstruction

\section{Introduction}

Afferent loop syndrome has been defined as an acute or chronic mechanical obstruction of the afferent limb following subtotal gastrectomy with Billroth II anastomosis or duodenojejunostomy following a pyloric-preserving Whipple procedure (Table 1). ${ }^{1}$ It may present with abdominal pain alone or a variety of pancreaticobiliary problems to include pancreatitis, cholangitis, or obstructive jaundice, particularly in patients who have concomitant biliary or pancreatic anastomoses (Table 2). ${ }^{2}$ Similar symptoms occur when Roux-en-Y limbs are obstructed or there is obstruction of the afferent limbs connected to them. ${ }^{3-8}$ Clinical complaints are dependent, in part, upon the site of obstruction, the presence of concomitant pancreaticobiliary anastomoses, and whether the obstruction is acute and related to torsion, adhesions,

Table 1 Etiology of Afferent/Roux Limb Obstruction

\begin{tabular}{ll}
\hline \multicolumn{1}{c}{ Intrinsic } & \multicolumn{1}{c}{ Extrinsic } \\
\hline Neoplasm & Neoplasm \\
Marginal ulcer & Adhesions/internal hernia \\
Irradiation & Transverse mesocolon defect with torsion \\
\hline
\end{tabular}

internal hernia or marginal ulceration, or as a consequence of fixed anatomic stenoses. The latter can be intrinsic to include recurrent or residual neoplasm or irradiation damage to the limb, or extrinsic, most commonly a consequence of stenosis of the limb having been tunneled through the transverse mesocolon.

Approached percutaneously, ${ }^{9-11}$ surgically, ${ }^{12-19}$ and endoscopically, $^{20-23}$ contingent upon clinical presentation, patient fitness, and institutional expertise, this review will focus on evolving endoscopic approaches to the obstructed afferent and Roux limbs.

Table 2 Clinical Manifestations of Afferent/Roux Limb Obstruction

Pain

Nausea and vomiting

Cholestasis/cholangitis*

Pancreatitis*

\pm Painless abdominal mass

\pm Enterolith formation

\pm Fistula to obstructed limb (presupposes surgical or percutaneous intervention)

*More common with concomitant pancreaticobiliary anastomoses to the obstructed limb.

Digestive Disease Institute, Virginia Mason Medical Center, Seattle, WA, USA

Received August 24, 2015; Revised September 25, 2015; Accepted September 30, 2015

* Corresponding author. Digestive Disease Institute, Virginia Mason Medical Center, University of Washington, 1100 9th Ave. Seattle, Washington 98101, USA.

E-mail address: Richard.Kozarek@virginiamason.org (R.A. Kozarek). 


\section{Afferent Limb Obstruction}

The endoscopic treatment of afferent limb obstruction is contingent upon the clinical presentation and the underlying condition of the patient. Our group has previously defined a 13\% incidence in 186 patients undergoing pancreaticoduodenectomy followed by chemoirradiation for pancreatic malignancy. ${ }^{2}$ The median time to diagnosis was 1-2 years (0.03-12.3 years). Etiologies included radiation enteropathy in 38\%, recurrent malignancy in 33\%, marginal ulcers in 5\%, and anastomotic strictures in $4 \%$ of patients. Other causes included adhesions and fixed angulations. Fifty percent of patients presented with obstructive jaundice or cholangitis, 21\% with nausea and vomiting and 29\% with pain with or without concomitant lipase elevations. Over a median follow-up of 2.4 years, 15/24 patients (62.5\%) required endoscopic therapy to include balloon dilation (3), luminal double pigtail stent placement (8), both (1), biliary stenting (2), and selfexpandable metal stent (SEMS) (1). Five patients required percutaneous biliary drainage and 4 were treated conservatively with antibiotics. No patient was thought to be a surgical candidate. Using multivariate analysis, only survival of 2 years or longer was associated with development of afferent limb syndrome after controlling for covariates to include age, sex, type of surgery, or adjuvant chemoirradiation.

Although balloon dilation alone has been used for anastomotic afferent limb strictures, reoperative surgery is at times required, particularly for patients with benign disease. Recurrent malignancy with afferent loop obstruction is usually best handled by placement of a SEMS (Fig. 1). In a recent publication in which our group placed SEMS in approximately 300 patients with gastric outlet obstruction, 6 individuals with Billroth II or duodenojejunostomy anatomy required concomitant afferent limb decompression. ${ }^{24}$ For those who had Billroth II anatomy, side-by-side enteral SEMS were used, whereas with those individuals who had a duodenojejunostomy, an enteral stent was placed from the bulb into the efferent loop. A biliary SEMS was then placed through the proximal enteral stent mesh into the afferent limb. Contingent upon the length of the afferent limb and the site of obstruction, comparable palliation has been achieved percutaneously. For instance, Han et $\mathrm{al}^{10}$ treated 13 consecutive patients, 9 orally and 4 through a transhepatic biliary drainage tract. Twelve of 13 patients normalized their elevated liver function tests and 1 required a surgical jejunojejunostomy. No complications were reported. Sato et $\mathrm{al}^{9}{ }^{9}$ in turn treated 8 patients with afferent limb syndrome (6) or postoperative pancreatic fistula (2) following pancreaticoduodenectomy for malignancy by accessing the afferent limb percutaneously. Drains were placed into the afferent limbs in 6 patients in the fistula tract in 1, and into the pancreatic duct in 1 . Clinical success was reported as $87.5 \%$, and 2 patients had metallic stents inserted for recurrent malignancy. Mean catheter indwelling time was 143 days and no major complications were reported. Four patients had percutaneous tubes successfully removed. There have been no controlled trials comparing efficacy or side effect profiles in patients treated surgically, percutaneously, or endoscopically.
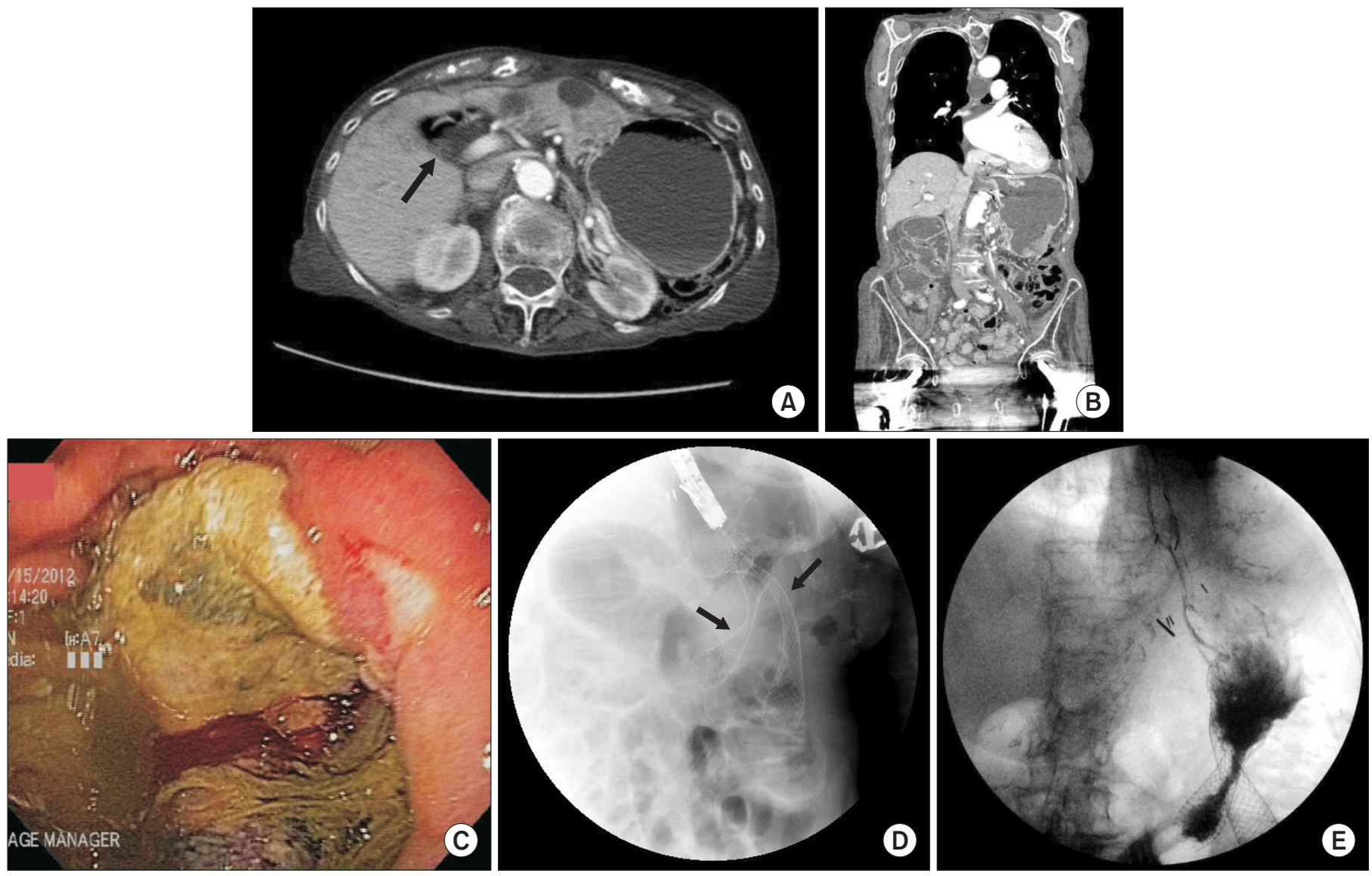

Fig. 1. (A, B) Computed tomography scan demonstrating dilated stomach and biliary tree (arrow) in this patient with malignant obstruction of the afferent and efferent limbs in this patient with Billroth II anatomy. Endoscopy demonstrates ulcerated anastomosis (C) treated with afferent and efferent self-expandable metal stent (arrows) (D). (E) Stent patency demonstrated by barium swallow in this 102-year-old patient palliated 4 months until death. 
Whereas percutaneous approaches may be associated with bleeding or bile leak, endoscopic treatment carries the risk of local perforation and stent migration. Surgery, in turn, carries risks of postoperative ileus in addition to pulmonary atelectasis, venous thrombosis and embolism and is better employed in patients with benign disorders (Table 3).

\section{Roux-en-Y Obstruction}

As with afferent limb obstructions, obstruction of the Roux limb can be a consequence of benign or malignant disease. Moreover, the obstruction may be at the proximal (gastrojejunostomy in Roux-en-Y gastric bypass) or distal anastomosis (jejunojejunostomy) or within an afferent limb connected to a Roux limb (e.g.,

Table 3 Endoscopic Treatment of Afferent and Roux-en-Y Obstruction

\begin{tabular}{lc}
\hline \multicolumn{1}{c}{ Benign disease } & Malignancy \\
\hline Balloon dilation & SEMS \\
Pigtail stent placement & \\
\pm C-SEMS/LAS & \\
\hline
\end{tabular}

SEMS, self-expandable metal stent; C, covered; LAS, lumen-apposing stent.
Roux-en-Y hepaticojejunostomy). With the exception of patients with a pancreaticobiliary bypass, most Roux limbs are now accessible using single or double balloon enteroscopes or with the use of a rotational self-advancing overtube. Although access has been primarily used to perform endoscopic retrograde cholangiopancreatography in patients with postoperative anatomy, SEMS can be placed through the enteroscope overtube under fluoroscopic control after removal of the endoscope. ${ }^{21-24}$ This overcomes the small enteroscope working channel $(2.8 \mathrm{~mm})$ which precludes passage of currently marketed SEMS delivery catheters.

Patients with benign disease causing obstruction of a long Roux limb or the afferent limb connecting to it provide a particular challenge. Contingent upon the etiology of the underlying obstruction, 1 or more double pigtail stents can be placed for problems such as acute cholangitis as a temporizing measure for definitive surgery (Fig. 2).

Alternatively, covered-SEMS can be placed through an overtube with the attendant risks of stent migration and erosion in high surgical risk patients. Finally, lumen-apposing SEMS have the potential to be placed even in completely obstructed lumens as depicted in Fig. 3. Originally designed to be placed through an echoendoscope into a contiguous pancreatic fluid collection for a cystgastrostomy, this technology has been used to perform cholecysto- and choledochoduodenostomies as well as gastroje-
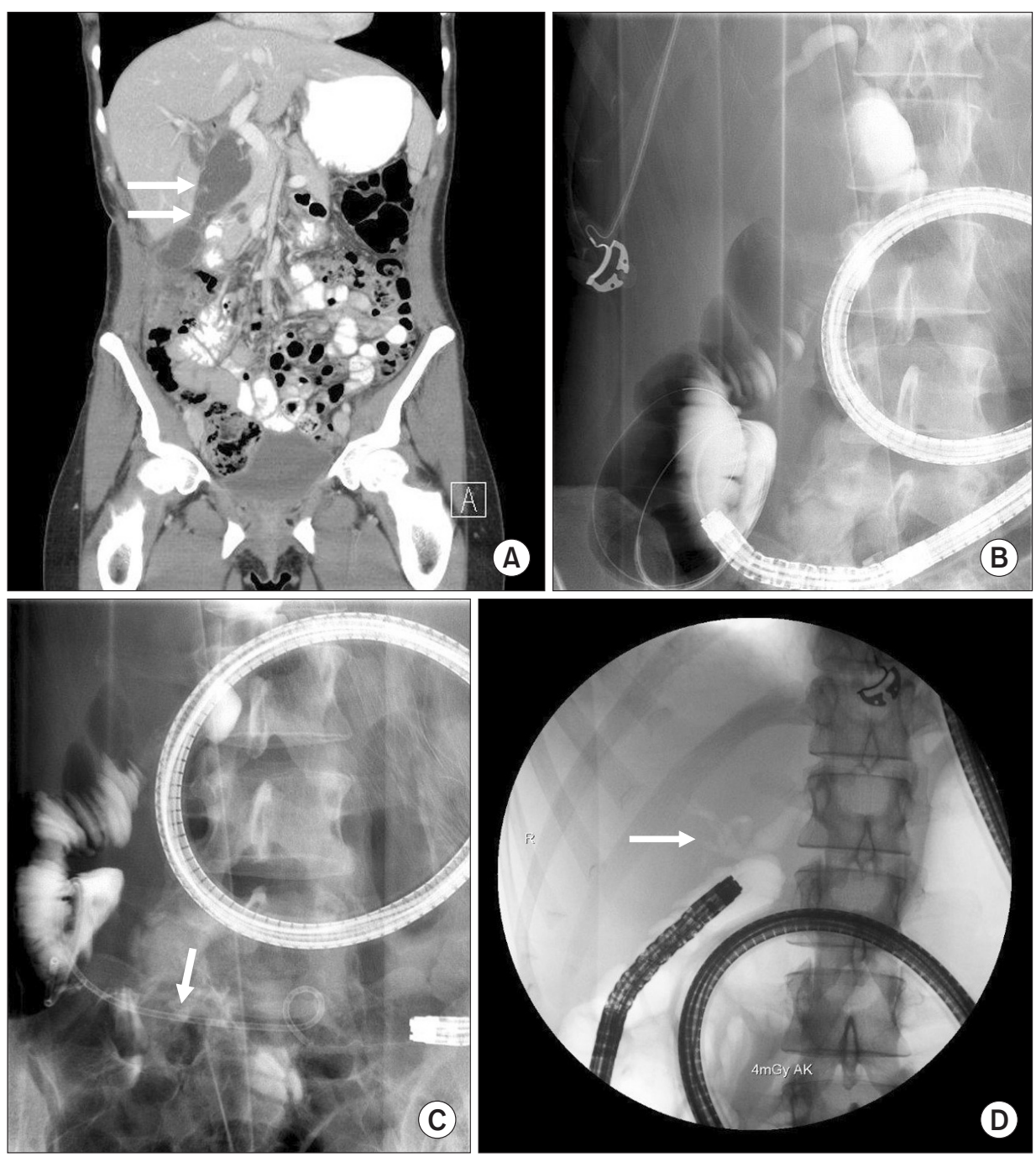

Fig. 2. (A) Dilated afferent limb (arrows) in a patient with Roux-en-Y hepaticojejunostomy who presented with cholangitis. Balloon assisted enteroscopy demonstrating a dilated and obstructed afferent limb (B) treated with a $7 \mathrm{Fr} / 15 \mathrm{~cm}$ double pigtail stent (arrow) (C). (D) Subsequent surgical exploration demonstrated torsion of the afferent limb as it exited the transverse mesocolon. Postoperative enteroscopy demonstrated a widely patent afferent limb (arrow). Note air in the biliary tree demonstrating intrahepatic duct dilation in this patient whose original surgery was undertaken for choledochal cyst. 

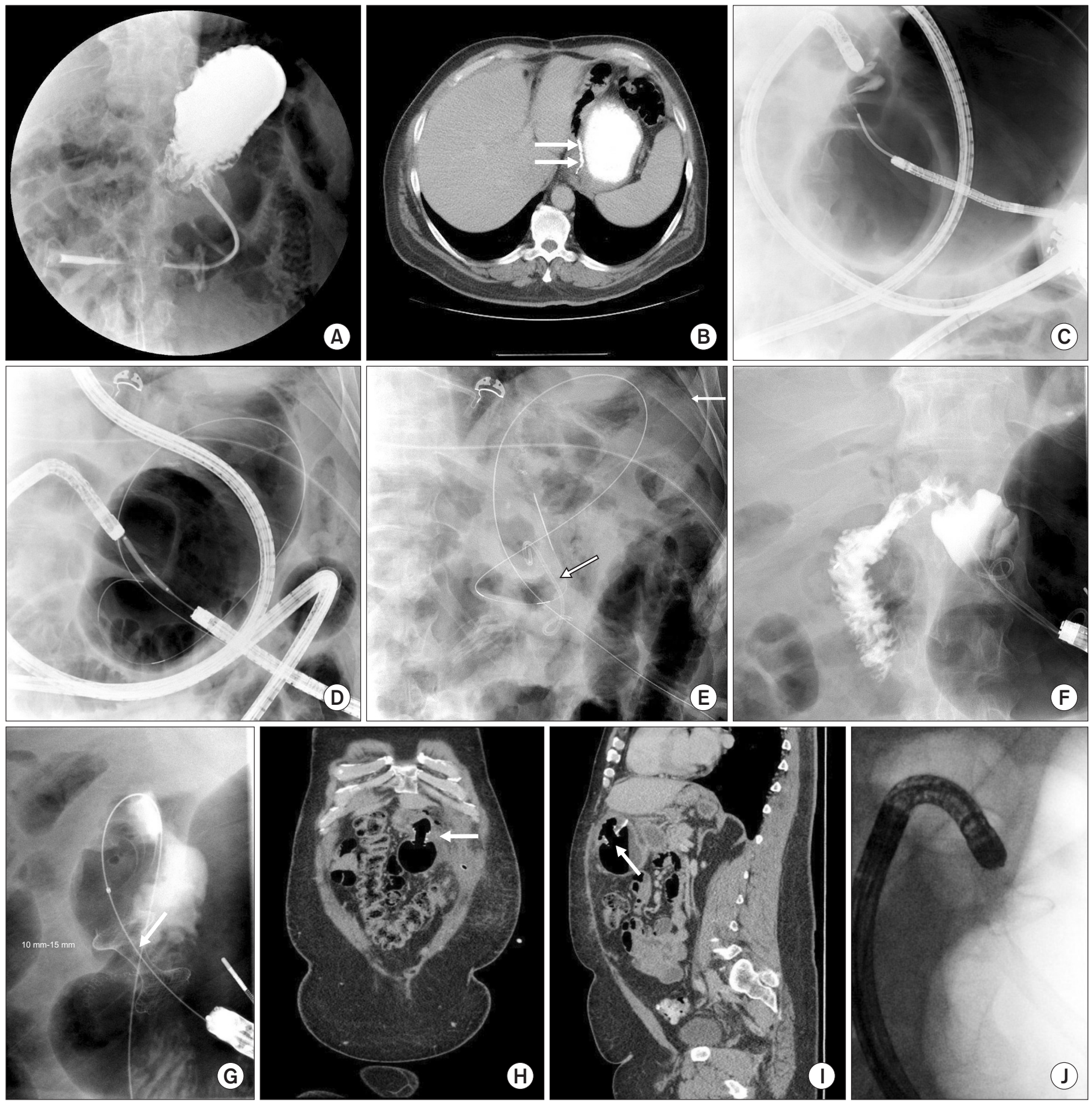

Fig. 3. (A) Gastrostomy tube study in patient who had previously undergone Roux-en-Y gastric bypass procedure for morbid obesity. (B) Note surgical staple line (arrows). Gastrostomy was placed in conjunction with pyloric closure and duodenal ulcer oversew for a perforated duodenal ulcer. Six months later, pyloric obstruction persisted requiring ongoing gastric decompression. Following percutaneous endoscopic gastrostomy (PEG) tract dilation and access into the disconnected stomach, a balloon assisted enteroscope is placed per os to visualize the obstructed duodenum. (C) A sclerotherapy needle is used through the PEG scope to assure a safe tract into the duodenal bulb. Following balloon dilation (D), a 7 Fr double pigtail stent (arrows) is placed through the stomach into the duodenum (E). (F) Note contrast injection into the C-loop alongside the stent. (G) A 15 mm lumen-apposing stent (LAS) self-expandable metal stents (Axios; Boston Scientific, Natick, MA, USA) was subsequently placed (arrow). Note patent prosthesis (arrows) (H, I) on subsequent computed tomography scan allowing G tube removal followed by removal of the LAS 4 weeks later (J). Case is courtesy of Andrew Ross, MD, Virginia Mason Medical Center.

junostomies. ${ }^{25}$ Its application in distal Roux limbs requires access through an overtube or adult colonoscope or a loop of proximal bowel contiguous to the site of obstruction and accessible by an endoscopic ultrasonography scope. ${ }^{26}$ There have been no compar- ative studies using these various methods of luminal decompression in patients with Roux-en-Y obstruction, to date, although endoscopic treatments in high risk patients minimize the risks of bleeding or bile leak compared with percutaneous transhepatic 


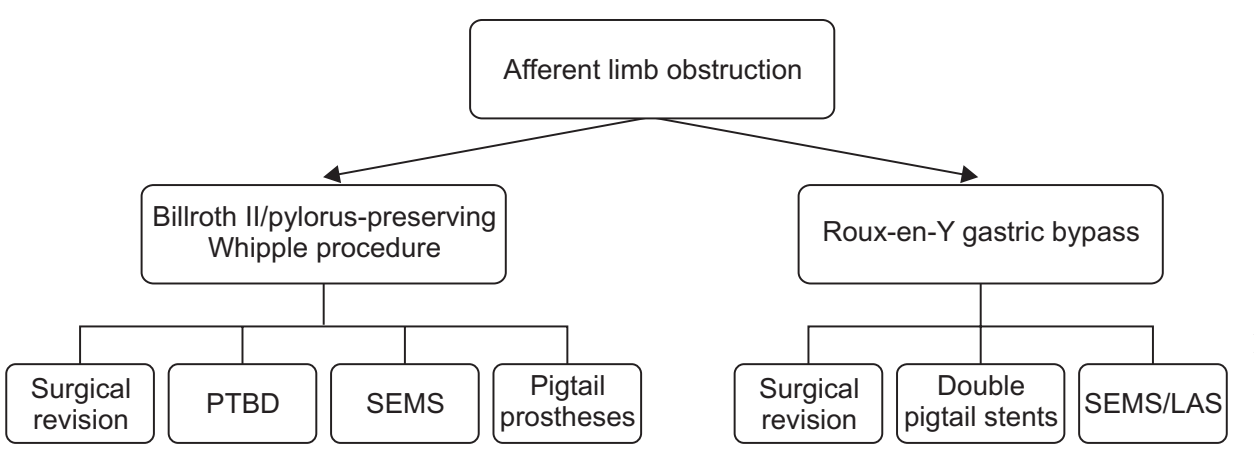

Fig. 4. Overview of treatment modalities for afferent and Roux-en-Y limb obstruction. PTBD, percutaneous transhepatic biliary drainage; SEMS, self-expandable metal stents can be placed endoscopically or through PTBD tract; LAS, lumenapposing (metal) stent. biliary drainage and the postoperative complications of revisional surgery.

As of this writing, endoscopic, percutaneous and laparoscopic techniques for the treatment of afferent and Roux-en-Y obstruction continue to evolve, hybridize, and be tested (Fig. 4). The author awaits further technologic advance with impatience (Table 3).

\section{Conflicts of Interest}

No potential conflict of interest relevant to this article was reported.

\section{References}

1. Juan YH, Yu CY, Hsu HH, Huang GS, Chan DC, Liu CH, et al. Using multidetectorrow CT for the diagnosis of afferent loop syndrome following gastroenterostomy reconstruction. Yonsei Med J. 2011;52:574-80.

2. Pannala R, Brandabur JJ, Gan SI, Gluck M, Irani S, Patterson DJ, et al. Afferent limb syndrome and delayed GI problems after pancreaticoduodenectomy for pancreatic cancer: single-center, 14-year experience. Gastrointest Endosc. 2011;74: 295-302.

3. Elms L, Moon RC, Varnadore S, Teixeira AF, Jawad MA. Causes of small bowel obstruction after Roux-en-Y gastric bypass: a review of 2,395 cases at a single institution. Surg Endosc. 2014;28:1624-8.

4. Brolin RE, Kella VN. Impact of complete mesenteric closure on small bowel obstruction and internal mesenteric hernia after laparoscopic Roux-en-Y gastric bypass. Surg Obes Relat Dis. 2013;9:850-4.

5. Griffith PS, Birch DW, Sharma AM, Karmali S. Managing complications associated with laparoscopic Roux-en-Y gastric bypass for morbid obesity. Can J Surg. 2012; 55:329-36

6. Nandipati KC, Lin E, Husain F, Srinivasan J, Sweeney JF, Davis SS. Counterclockwise rotation of Roux-en-Y limb significantly reduces internal herniation in laparoscopic RouX-en-Y gastric bypass (LRYGB). J Gastrointest Surg. 2012;16:675-81.

7. Uchida H, Sakamoto S, Hamano I, Kobayashi M, Kitajima T, Shigeta T, et al. Urgent living donor liver transplantation for biliary atresia complicated by a strangulated internal hernia at Roux-en Y limb: a case report. Ann Transplant. 2014; 19:149-52.

8. Aoki M, Saka M, Morita S, Fukagawa T, Katai H. Afferent loop obstruction after distal gastrectomy with Roux-en-Y reconstruction. World J Surg. 2010;34:2389-92.

9. Sato Y, Inaba Y, Murata S, Yamaura H, Kato M, Kawada H, et al. Percutaneous drainage for afferent limb syndrome and pancreatic fistula via the blind end of the jejunal limb after pancreatoduodenectomy or bile duct resection. $J$ Vasc Interv Radiol. 2015;26:566-72.

10. Han K, Song HY, Kim JH, Park JH, Nam DH, Ryu MH, et al. Afferent loop syndrome: treatment by means of the placement of dual stents. AJR Am J Roentgenol. 2012;199:W761-6.

11. Hosokawa I, Kato A, Shimizu H, Furukawa K, Miyazaki M. Percutaneous tran- shepatic metallic stent insertion for malignant afferent loop obstruction following pancreaticoduodenectomy: a case report. J Med Case Rep. 2012;6:198.

12. Blouhos K, Boulas KA, Tsiomita E, Papageorgiou I, Ioannidis K, Hatzigeorgiadis A. Pancreaticojejuno-jejunostomy during reconstruction of the afferent loop in surgery of radiation-induced afferent loop obstruction following pancreaticoduodenectomy with Roux-en-Y reconstruction. Updates Surg. 2014;66:51-7.

13. Tsalis K, Antoniou N, Koukouritaki Z, Patridas D, Sakkas L, Kyziridis D, et al. Successful treatment of recurrent cholangitis by constructing a hepaticojejunostomy with long Roux-en-Y limb in a long-term surviving patient after a Whipple procedure for pancreatic adenocarcinoma. Am J Case Rep. 2014;15:348-51.

14. Marangoni G, Ali A, Faraj W, Heaton N, Rela M. Clinical features and treatment of sump syndrome following hepaticojejunostomy. Hepatobiliary Pancreat Dis Int. 2011;10:261-4.

15. Leyba JL, Navarrete S, Navarrete Llopis S, Sanchez N, Gamboa A. Laparoscopic technique for hernia reduction and mesenteric defect closure in patients with internal hernia as a postoperative complication of laparoscopic Roux-en-Y gastric bypass. Surg Laparosc Endosc Percutan Tech. 2012;22:e182-5.

16. Aghajani E, Jacobsen HJ, Nergaard BJ, Hedenbro JL, Leifson BG, Gislason H. Internal hernia after gastric bypass: a new and simplified technique for laparoscopic primary closure of the mesenteric defects. J Gastrointest Surg. 2012;16:641-5.

17. Marr B, Yenumula P. Roux limb volvulus in laparoscopic Roux-en-Y gastric bypass due to Roux limb stabilization suture: case series. Obes Surg. 2012;22:4-7.

18. Abasbassi M, Pottel H, Deylgat B, Vansteenkiste F, Van Rooy F, Devriendt D, et al. Small bowel obstruction after antecolic antegastric laparoscopic Roux-en-Y gastric bypass without division of small bowel mesentery: a single-centre, 7-year review. Obes Surg. 2011;21:1822-7.

19. Shimizu H, Maia M, Kroh M, Schauer PR, Brethauer SA. Surgical management of early small bowel obstruction after laparoscopic Roux-en-Y gastric bypass. Surg Obes Relat Dis. 2013;9:718-24.

20. Fujii M, Ishiyama S, Saito H, Ito M, Fujiwara A, Niguma T, et al. Metallic stent insertion with double-balloon endoscopy for malignant afferent loop obstruction. World J Gastrointest Endosc. 2015;7:665-9.

21. Sakai A, Shiomi H, Okabe Y, Yagi Y, Kobayashi T, Shiomi Y, et al. Effectiveness of endoscopic self-expandable metal stent placement for afferent loop obstruction caused by pancreatic cancer recurrence after pancreaticoduodenectomy. Clin J Gastroenterol. 2015;8:103-7.

22. Shugo H, Hodo Y, Yoneshima M. Endoscopic metallic stent insertion for malignant afferent loop obstruction using balloon-assisted enteroscopy: a case report. Am J Gastroenterol. 2015;110:355-7.

23. Tsutsumi K, Kato H, Tomoda T, Matsumoto K, Sakakihara I, Yamamoto N, et al. Partial stent-in-stent placement of biliary metallic stents using a short doubleballoon enteroscopy. World J Gastroenterol. 2012;18:6674-6.

24. Oh SY, Edwards A, Mandelson M, Ross A, Irani S, Larsen M, et al. Survival and clinical outcome after endoscopic duodenal stent placement for malignant gastric outlet obstruction: comparison of pancreatic cancer and nonpancreatic cancer. Gastrointest Endosc. 2015;82:460-8.

25. Weilert F, Binmoeller K. Specially designed stents for transluminal drainage. Gastrointest Interv. 2015;4:40-5.

26. Perez-Miranda M, Sanchez-Ocaña R, de la Serna Higuera C, Diez-Redondo P, Nuñez H, Vallecillo MA. Transenteric anastomosis with lumen-apposing metal stent as a conduit for iterative endotherapy of malignant biliary obstruction in altered anatomy. Gastrointest Endosc. 2014;80:339. 